\title{
Harmoni dan Narasi Kosmos
}

\author{
Iqbal Prabawa Wiguna \\ Program Studi Seni Rupa Intermedia, Universitas Telkom
}

\begin{abstract}
For all his life Johannes Kepler seeking for harmony. Kepler is best known for his laws of planetary movement. He is also a polymath working in the intersection between contemporary sciences such as astronomy, math, physics, optics, astrology, music theory, meteorology dan history. After spending years exploring those different disciplines, he later learned he was actually longing for the harmony. His fascination over harmony in nature kept growing up, in his last days Kepler was still trying to finish a book he started since he was still a scholar. This book is called Somnium. Somnium itself is the Latin word for 'dream,' a word that make sense if you read the whole chapter. The main idea for this project is Kepler's fascination over the harmony in celestial object, thus he tried to convince people that Copernicus heliocentrism is the absolute truest way to understand how our solar system works. The idea of making narative came up to Kepler's mind as he turned his research into a fiction, a story about a boy who makes his journey to the moon to help his mother for being accused of being a witch. Similiarly to the boy, Kepler's mother is also accused for witchcraft. So Somnium was not really just a scientific book but in some part of them, there is also some biographical facts and fiction. By knowing the pattern in nature we can understand that the nature is in order and there is a grand design hidden in layers. Just like Kepler that are fascinated by the order of nature, 'Somnium' in this work is also talks about the pattern and harmony the curiousity for nature that represented in geometrical objet and natural study, and also about the old knowledge where science, art and spirituality is learnt through one form knowledge.
\end{abstract}

Keywords: Harmoni, Kepler, Narasi, Pola, Somnium.

\section{PENDAHULUAN}

Perkembangan saintifik dari alam semesta dikenali memiliki keteraturan (kosmos dan bukanlah chaos) yang dimulai ketika filsuf-filsuf alam dari Yunani berpendapat jika alam dapat dirasionalkan. Terlebih lagi dengan dimulainya space age atau era eksplorasi antariksa dan banyaknya teknik baru dalam riset saintifik, cara kita memandang hidup sekali lagi diperluas dengan melihat hidup sebagai suatu fenomena planetary. Komputerisasi dan teknologi satelit telah banyak mengubah cara pandang kita, terlebih sejak tahun 80'an, observasi satelit telah mengubah cara pandang kita sebagai "makhluk planet". Bumi layaknya sebuah kapal antariksa raksasa dapat dilihat secara keseluruhan, cara kita memandang alam pun berubah (B.Botkin 10). 
Teknologi dan alam di era kontemporer ini memiliki kualitas spiritual di dalamnya. Cara pandang kita terhadap alam telah berubah. Dahulu sains seakan menghilangkan misteri yang terkesan spiritual atau bermakna relijius dalam alam. Namun hubungan sains, teknologi dan alam saat ini justru berubah seiring berjalannya babak demi babak dalam sejarah yang kita jalani. Dengan memberi sebuah pandangan baru dalam kajian ontologis dan narasi dalam proses berkesenian.

Penulis membuat karya rupa yang terinspirasi dari tulisan science-fiction yang berbicara tentang alam dan harmoninya serta hubungan seni sains dan spiritualitas melalui sains 'lama' yang ditampilkan kembali dengan presentasi seni rupa. Kekuatan narasi mampu membuat kita masuk ke sebuah alam baru yang bebas dari rasionalitas. Dengan menggunakan keunikan sains fiksi, literatur karya menjadi memiliki lapisan makna.

Karya naratif termasuk ke dalam seni, karena narasi adalah peristiwa yang terjadi dari waktu ke waktu. Peristiwa ini dapat diubah menjadi sebuah gambar tunggal yang menyiratkan sesuatu yang akan atau telah terjadi.

Jejak seni sebagai narasi bisa dilihat dari buku On Painting (1435) oleh Leon Battista Alberti dalam buku tersebut lukisan adalah Historia, yang berarti story atau cerita. Dia bersikeras membandingkan seni rupa dengan literatur/sastra, karena kata 'komposisi' telah lama digunakan dalam sastra. Namun seni modern pada akhir abad 19 menolak narasi dalam karya mereka. Mereka bahkan berusaha membersihkan seni lukis dan patung dari narasi karena mendongeng atau bercerita dianggap sebagai pekerjaan penulis bukanlah pekerjaan seniman. Pada tahun 20'an para seniman bersikeras dengan abstrak ekspressionis-nya dan menganggap tabu pada narasi. Akhirnya di awal 60'an seniman pop justru sulit menolak mengembalikan narasi pada dunia seni.

Dalam dunia sastra penyampaian literasi berdasarkan riset saintifik, namun masih menggunakan setting plot berdasar imajinasi pengarang ada dalam genre sains fiksi. Salah satu buku sains-fiction pertama ternyata tidaklah ditulis oleh seorang pujangga atau penyair, namun oleh seorang ilmuwan abad ke 17 yang juga seorang polymath (orang yang menguasai lebih dari satu bidang ilmu) bernama Johannes Kepler.

\section{Johaness Kepler}

Karya Somnium adalah spekulasi Kepler yang bersifat imajinatif tentang bagaimana bumi terlihat dari bulan dan gambaran imajinatif dari bulan itu sendiri. Kepler tidak dikenal sebagai seorang penulis sastra namun sebagai seorang astronom dan sebagai seorang saintis. Kepler adalah seseorang dengan tingkat intelegensia tinggi. Ide awal karya Somnium jauh ketika Kepler masih berstatus pelajar. Pada saat itu, Ia percaya pada teori heliosentrisme dari Copernicus. Teori ini adalah teori yang menjadikan 
Matahari sebagai pusat tata surya dan bukan bumi, karena bumi sendiri berputar mengelilingi matahari. Namun Kepler kesulitan membuktikan teori ini, karena tubuh kita sendiri tak dapat merasakan gerakan berputar bumi karena adanya gaya gravitasi. Bernagkat dari ide dasar bagaimana jika ia berada di luar angkasa, Kepler membayangkan jika ia dapat melihat bumi berputar dari bulan.

Bukanlah jalan cerita dari Somnium yang menjadikan karya ini menarik melainkan genre literasinya-lah yang menarik. Kepler menggunakan detail saintifik untuk dijadikan model "dunia lain" yang ia ciptakan di bulan. Hal ini yang menjadikan Somnium sebagai salah satu karya pertama dan penting untuk genre science-fiction. Didalam karya ini Kepler banyak menggunakan catatan kaki untuk menjelaskan sisi saintifik dan allegori yang terkadang lebih menarik daripada jalan ceritanya itu sendiri.

Catatan kaki ini sendiri berisi interpretasi yang bersifat menjelaskan. Hal ini membuat karya Somnium walaupun merupakan karya fantasi yang bersifat supranatural namun memiliki kekuatan saintifik yang membuat karya ini memiliki allegori yang kaya akan penafsiran namun tetap dapat dijelaskan secara saintifik. Model narasi dalam Somnium dapat dilihat sebagai faktor kunci yang berkontribusi pada signifikasi saintifik pada karya ini narasi atau storytelling telah memegang peranan penting dalam dunia seni rupa kontemporer.
Seiring dengan berkembangnya tren dokumentasi dalam dunia seni.

Entah apakah itu historis, politikal, atau berdasarkan cerita personal, tendensi naratif dalam seni kontemporer mencakup dari faktual dan berdasar kenyataaan yang ada sampai dengan yang bersifat imajinatif seperti dongeng.

Kepler menggunakan narasi dalam usahanya menawarkan sebuah allegori mimpi kosmologikal yang sebenarnya berisi dokumentasi data riset dan juga studinya terhadap benda langit seperti bulan. Pendekatan ini sangat menarik karena menampilkan "perjalanan kosmik" dengan cara baru.

Pendekatan naratif dalam karya ini berhubungan dengan relevansi spiritual dimana mimpi berfungsi untuk menghasilkan rasa dislokasi kesadaran (consciousness) menjadi ketidaksadaran (unconsciousness). Mimpi juga menjadi ruang (space) yang memiliki multipretasi, seperti natural dan supranatural, realita dan fantasi atau intepretasi yang dapat dijelaskan dan visi yang dapat dilukiskan. Perbatasan antara mitos dan kesadaran saintifik. Dalam bukunya Imagining the Unimaginable, Lambert cenderung memandang alam mimpi sebagai kanvas kosong. Mimpi adalah sebuah alat, yang setia dan berfungsi untuk melayani imajinasi.

\section{Harmoni dan Pola}

Bumi sebagai sebuah planet memiliki semua karakteristik dan susunan yang tepat untuk mendukung terjadinya 
kehidupan. Misalnya bumi mampu menampung atmosfer dengan susunan yang tepat sehingga kehidupan dapat berevolusi dan eksis. Ia cukup dekat dengan matahari untuk memberi suhu hangat namun tidak terlalu dekat untuk menjadi panas. Bumi juga berotasi di sumbunya sehingga bagian bumi yang terkena sinar Mmatahari mendapat sinar yang cukup sementara bagian yang tidak terkena tidaklah menjadi terlalu dingin.

Alam semesta ini memiliki susunan yang kompleks dan memiliki berbagai level dari bio-kimia sampai astronomis. Melebihi dari apa yang disebut kebetulan semata, dan sering kali membuat kita terpukau sekaligus kebingungan menganalisa fenomena alam yang hadir di sekitar kita yang akhirnya menjadi seperti puzzle yang penuh kontradiksi.

Sains seharusnya berperan untuk membantu menjelaskan dunia di sekitar kita tanpa mengambil jalan lain seperti memiliki maksud-maksud tertentu. Seperti menjadikan alam semesta sebagai sebuah mesin elegan yang kompleks yang fungsinya memenuhi kebutuhan hidup kita (B. Botkin 201).

Persepsi alam sebagai sebuah susunan yang teratur sudah banyak digunakan para saintis, naturalis, dan para konsevationis di abad 20, namun jika kita lihat kebelakang persepsi ini juga bergema di masa lalu. Keteraturan ini menarik para saintis di masa itu untuk menemukan jejak Sang Pencipta. Susunan yang kompleks dari alam semesta merupakan bukti penting untuk mendemonstrasikan kehadiran Sang Pencipta dan ciptaan yang memiliki fungsi dan tujuan tertentu.

Seperti yang disimpulkan oleh A.C. Crombie dalam bukunya Science, Art and Nature in Medieval and Modern thought (Hambledon Press, 1996) saintis, naturalis, dan para konservationis di abad 20 ini melalui observasi dengan hukum alam yang universal dari sains memiliki pandangan yang sama dengan filsuf di masa lalu dan pre-saintifik theologian: bahwa alam memiliki keteraturan yang sangat tinggi.

Dengan ini melalui sains ada kepercayaan yang sama dengan kepercayaan relijius dalam keseimbangan dalam susunan alam, dan susunan alam yang kompleks ini adalah bukti dari adanya yang agung dan bersifat ketuhanan.

Karena bukti adanya Tuhan di masa lalu dibuktikan dengan (1) fisiologi dan anatomi; contohnya Tuhan menciptakan mata pada makhluknya untuk melihat dunia dan untuk bersyukur pada pencipta atas ciptaanNya yang agung (2) adanya susunan Kosmik (3) bumi sebagai lingkungan yang pas untuk hidup dan bagaimana bumi memiliki segalanya bagi makhuk yang hidup di dalamnya untuk berevolusi dan bertahan hidup Johannes Kepler mencari harmoni. Harmoni bagi Kepler adalah bentuk ideal yang diekspresikan dengan berbagai cara. 
Semuanya berdasar pada hubungannya yang abadi dengan geometri. Ekspresi yang paling penting dalam harmoni secara literal adalah yang terbesar. Harmoni dalam skala terbesar berasal dari struktur semesta dan pergerakan pada bagianbagiannya. Karyanya tentang harmoni yang berhubungan dengan luar angkasa ini sangat dekat hubungannya dengan karyanya yang populer dan orisinal sebagai seorang astronomer. Dia percaya jika bumi yang bersifat sekular dan surga yang bersifat spiritual telah diciptakan melalui pergerakan planet-planet sebagai perwujudan dari prinsip harmoni dan asas rasional.

Karya Somnium yang terinspirasi tulisan Kepler adalah representasi dari interaksi dengan alam yang bersifat inner (personal) namun dengan kerangka yang bersifat rasional. Sebuah integrasi dari proses berkarya yang bersifat intuitif dan naratif dengan bantuan alat elektronik yang bersifat logis dan matematikal. Sebuah proses berkarya rupa yang menyegarkan dan mendorong penulis untuk mempelajari medium baru yang tujuannya memperkuat medium yang sebelumnya telah penulis kuasai untuk berkarya.

\section{PROSES BERKARYA}

Karya Somnium ini titik awalnya adalah ketertarikan pada harmoni yang terdapat pada alam. Dari situ dicarilah berbagai literatur yang berkaitan tentang alam dan harmoninya. Dengan menggunakan narasi Somnium sebuah literatur yang memiliki muatan sains dan fiksi secara bersamaan. Dengan setting dunia mimpi namun cerita mitos fiksi ilmiah ini justru menyampaikan gagasangagasan penulisnya dengan kerangkakerangka yang bersifat logis dan rasional namun bersifat spekulatif. Lebih penting lagi buku ini dibuat oleh Johannes Kepler yang karya-karyanya bertujuan untuk mencari harmoni di alam melalui pola-pola yang terdapat di alam semesta. Sebuah tantangan untuk mewujudkannya dalam bentuk karya seni rupa.

\section{Sketsa}

Karena berangkat dari novel Kepler tentang perjalanan mimpi ke bulan. Karya yang dibuat banyak menggunakan objek bulan yang telah diabstraksi. Karya terbagi menjadi dua bagian dimana bagian pertama adalah karya yang lebih bersifat instalatif dimana pada bagian ini terdapat tiga buah karya yang menggambarkan pola-pola alam yang bentuk dasarnya berasal dari studi astronomi dan geometri. Sementara pada bagian kedua adalah karya yang bersifat interaktif, karya ini seakan mengajak kita masuk kedalam kepala seorang saintis atau mungkin ruang mimpinya, dimana ada terdapat banyak peralatan untuk melakukan eksplorasi saintifik pada warna dan pola, karena Kepler yang merupakan seorang saintis maka kesan ruang sains di abad pertengahan sangat kuat pada karya. 

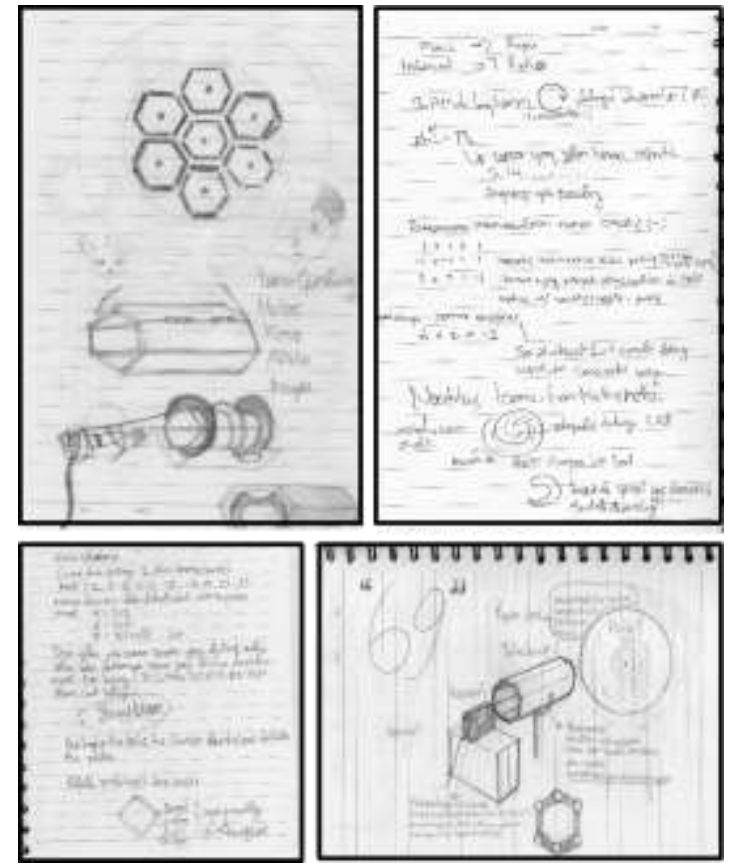

Gambar 1 Sketsa Manual

(sumber: Dokumentasi

Penulis)

\section{Pembuatan Karya}

Setelah sketsa sekarang kita memasuki tahap prototype tahap ini mulai mengeksplorasi kemungkinan berbagai medium untuk digunakan sebagai karya. Tahap protoype ini menjadi penting karena pada prosesnya beberapa karya yang sifatnya eksperimental pun pada akhirnya dapat ditampilkan mendukung konsep karya yang menampilkan studi sains lama. Penggunaan lampu $L E D$, motor servo yang dikendalikan mikrokontroller, selain sebagai elemen pendukung juga sebagai representasi teknologi yang merupakan turunan dari sains masa kini. Beberapa karya memanfaatkan objek alam seperti bebatuan sebagai representasi bentuk organik yang terdapat di alam adalah representasi bentuk organik yang terdapat di alam, selain itu untuk memperkuat bentukan astronomikal dari keadaan Bulan yang penuh dengan meteorit. Dengan memanfaatkan warna warna florescent yang tampak semakin kuat ketika latar semakin gelap bebatuan diwarnai dan dirangkai kedalam bentuk geometris yang merepresentasikan usaha manusia memahami alam .

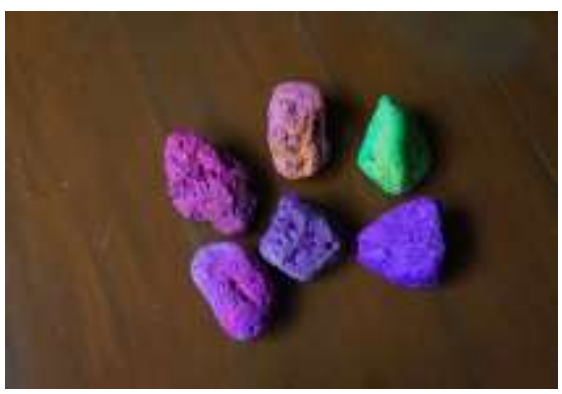

Gambar 2. Medium batu yang diwarnai cat flourescent (sumber: Dokumentasi Penulis)

Pada karya selanjutnya dibuat sebuah kabinet yang terinspirasi dari cabinet of curiosity di abad 15 ini yang menjadi referensi visual bagi penulis tabung reaksi yang identik laboratorium sains.

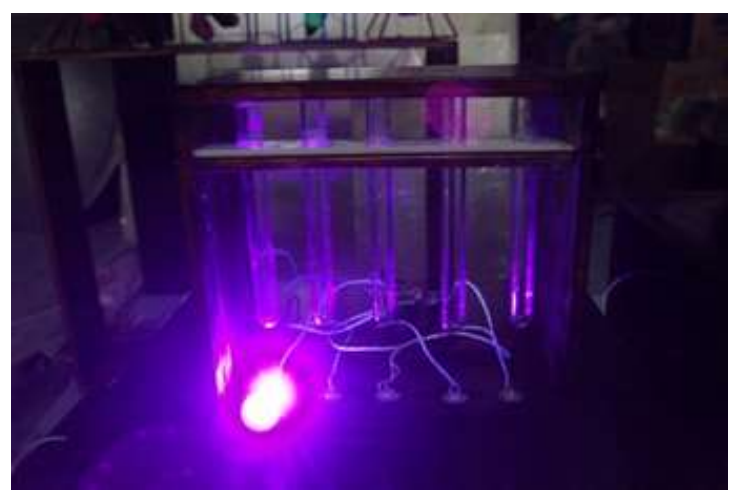

Gambar 3. Studi warna, tabung reaksi dengan lampu UV (sumber: Dokumentasi Penulis) 
Pada karya ini tabung reaksi akan diberi campuran cat berwarna warni dengan berat massa yang berbeda, karya ini berbicara tentang studi warna dan cahaya. Spektrum warna telah menjadi kajian studi yang menarik yang menghubungkan seni dan sains dalam cara yang imajinatif. Studi tentang benda langit di masa lalu juga banyak bersiftat spekulatif dan imajinatif yang membawa pada proses karya selanjutnya yang berbicara tentang studi geometri dan astronomi, karya ini menampilkan pola konstelasi yang direpresentasikan dengan benang flourescent yang membuat pola geometris sama seperti studi warna, studi pola ini juga dibuat dalam bentuk kabinet, benang dan pola konstelasi digambar ke dalam kabinet yang berisi batu-batu yang diwarnai flourescent dan lampu UV.

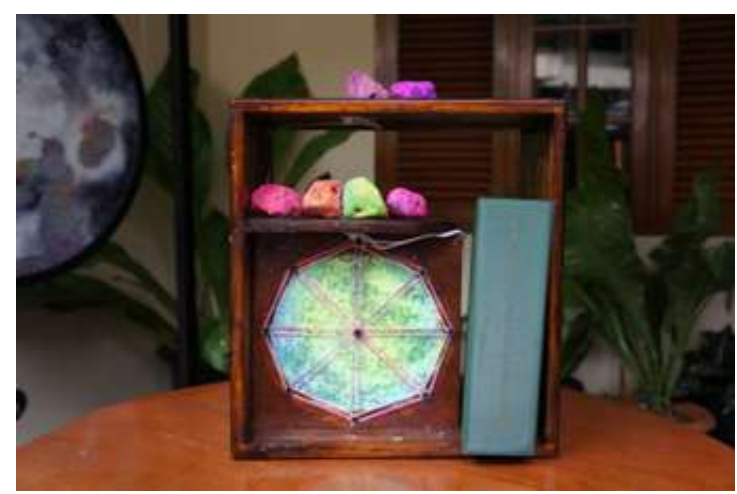

Gambar 4. Studi pola, pola konselasi bentuk geometris (sumber: Dokumentasi Penulis)

Berikutnya karya kaleidoskop, pada karya ini dibuat sebuah teleskop yang berhadapan dengan objek yang diberi pola dan mempunyai komponen elektronika didalamnya yang memungkinkan ia untuk berputar dan berubah-ubah warnanya. LED dan servo yang diatur oleh mikrokontroller digunakan untuk memperkuat karya kaleidoskop. Bentuk kaleidoskop yang menampilkan ilusi ruang menjadi penanda untuk masuk ke dalam alam ketidaksadaran, karya menunjuk pada pola-pola yang bergerak berputar dengan lampu yang berubah-ubah warnanya.

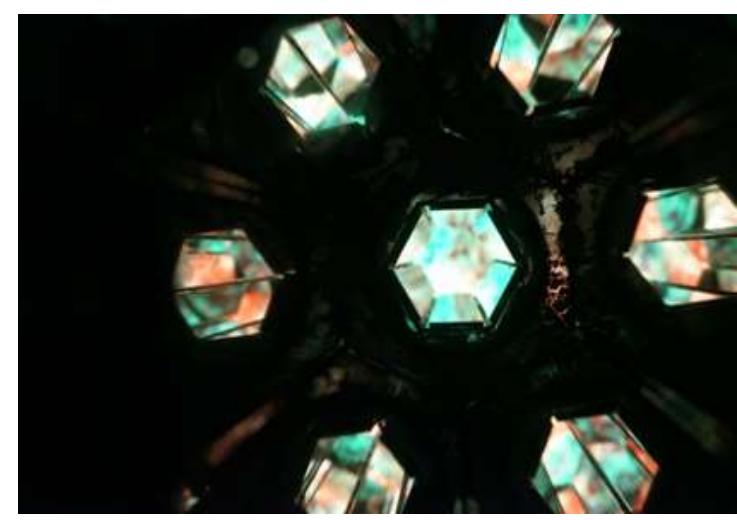

Gambar 5. Tampilan karya

kaleidoskop ruang mimpi

(sumber: Dokumentasi Penulis)

Perpaduan bentuk geometris dan polapola organik ditambah dengan efek cahaya dan kinetik diharap bisa memberi efek ilusi seperti ketika memasuki alam ketidaksadaran. Karya kabinet dan kaleidoskop yang telah selesai kemudian menjadi bagian dari keseluruhan aransemen karya yang bersifat instalatif. Secara keseluruhan karya menampilkan sebuah ruang kerja sosok saintis di abad 18 yang sedang memiliki ketertarikan terhadap hubungan manusia dan alam. Ia mempelajari pola, cahaya dan warna di dalam studionya. Pada bagian ini ruang studi diharapkan dapat membuat audiens seperti berada dalam pribadi si saintis. Dengan memanfaatkan perabot tua dan antik 
Penulis membangun sebuah ruang studi yang penuh dengan alat kreasi eksperimen si pemilik ruang tersebut.

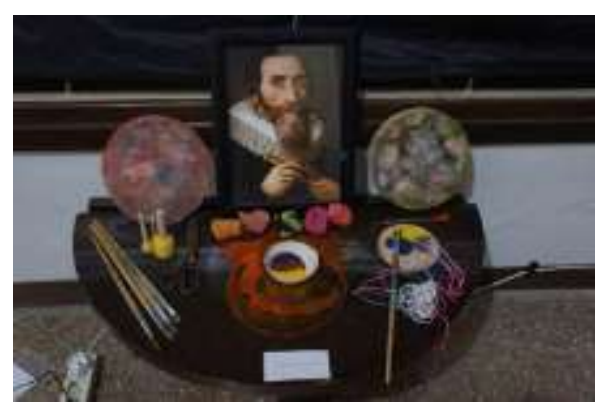

Gambar 6. Studi warna (sumber: Dokumentasi Penulis)

\section{Pembuatan Ruang Instalasi}

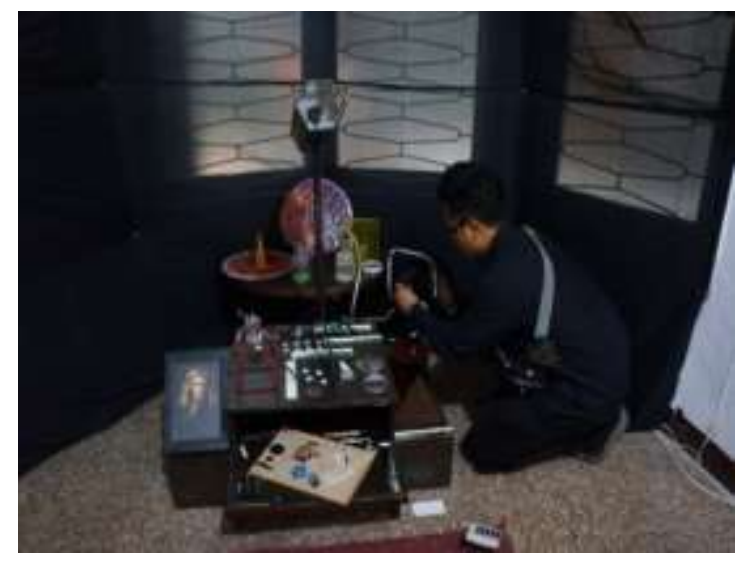

Gambar 7. Foto Pemasangan Instalasi (sumber: Dokumentasi Penulis)

Susunan karya ini dibangun menjadi kesatuan sebuah karya utuh yang merepresentasikan sains lama. Beberapa objek seperti lensa, tabung reaksi, bentuk pola, teleskop dan lainlain telah diubah dari bentuk aslinya menjadi bentuk yang tidak biasa namun masih menunjukkan identitas fungsinya

\section{TINJAUAN KARYA}

Karya Somnium adalah karya studi penulis terhadap pola warna dan juga bentuk-bentuk geometris, bentukan karya yang menyerupai ruang studi seorang saintis abad 18 sebagai representasi masa dimana ketika spritualitas, seni dan sains masih berada dalam satu koridor. Sains pada abad itu memiliki keterikatan yang kuat dengan seni. Seniman dan ilmuwan berpendapat ada keteraturan di dalam alam, dan jika ada grand design maka pastilah ada pengatur atau creator. Hal yang membuat sains, seni dan spiritualitas menjadi kesatuan untuk menciptakan harmoni kehidupan.

Teleskop yang ikon dunia astronomi di masa medieval masih menyimpan imajinasi spekulatif pada alam semesta. Bagi penulis teleskop adalah manifetasi bentuk teknologikal pertama yang merubah pandangan kita terhadap dunia. Semenjak ditemukannya teleskop para ilmuwan semakin tertantang untuk menjelajahi alam semesta dan mencari pola-pola tertentu yang dapat menjelaskan kita manusia dan alam semesta.

Pola pikir itulah yang membuat penulis berkarya dengan unsur rupa yang paling esensial yaitu warna pola dan tekstur. Ketiganya penulis susun hingga tercipta harmoni. Pada karya ini penulis mencoba membuat sebuah ruang dimana pengunjung dapat berinteraksi dengan karya yang berupa kaleidoskop mereka dapat merasakan persepsi yang berubah ketika karya dengan rotasi dan perubahan warnanya berubah-ubah. 

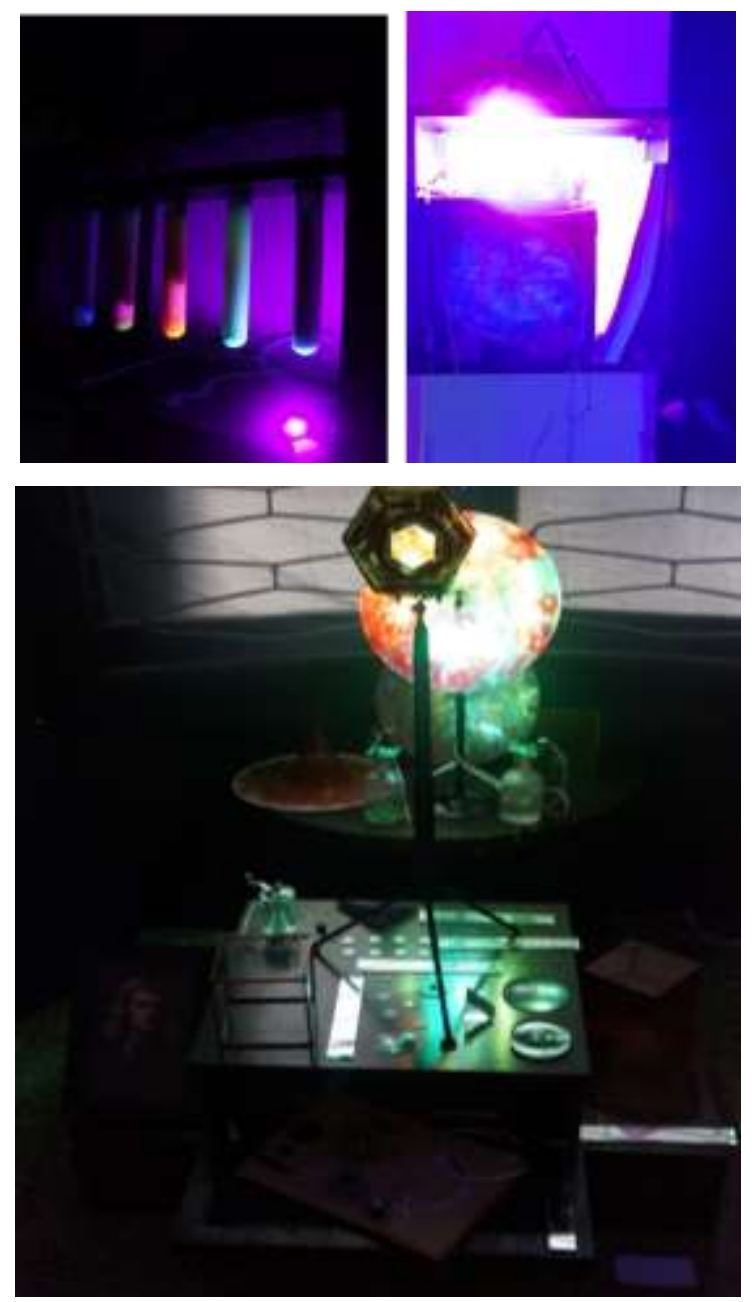

Gambar 8. Hasil akhir karya Somnium (sumber: Dokumentasi Penulis)

Telekop berbentuk kaleidoskop ini adalah karya yang menjelaskan bagaimana teknologi telah merubah persepsi kita dan bagaimana teknologi membantu kita mengenali pola-pola alam yang dalam karya berbentuk heksagonal. Penulis terinspirasi oleh tulisan Kepler bagaimana ia tertarik pada pola-pola alam semesta dan bentuk heksagonal yang ia temukan pada beberapa bentuk alam seperti butiran salju yang diperbesar. Bentuk heksagonal yang menjadi pola karya bulan dan kaleidoskop sendiri adalah salah satu bentuk yang paling banyak terdapat di alam, bentuk segi enam ini secara bentuk dapat menampung secara maksimal ruang yang ada, salah satu bentuk alami berdasar pola ini berasal dari sarang lebah. Para lebah secara intuitif membentuk pola ini untuk saranngya, membentuk susunan pola mereka sendiri.

Dengan menampilkan bentuk imajinatif dan surreal yang ide dasarnya berasal dari narasi pada periode abad pertengahan, dimana sains kuno berkembang menyajikan fakta astronomi dan fantasi imajinasi, permainan realita dan fantasi

\section{KESIMPULAN}

Usaha untuk menampilkan alam dalam sains modern dengan pendekatan seni menampilkan kesatuan karya yang menarik. Penggunaan narasi mimpi sebagai ruang multipretasi memberikan kemungkinan visi tak terbatas. Penggunaan narasi mimpi dan mitos adalah cara untuk mengembalikan pemahaman spiritualitas ke dalam alam dan sains teknologi. Dengan mengenali pola-pola alam kita akan mencapai kesadaran adanya aturan atau susunan yang terdapat dalam alam. Susunan itu tersembunyi dalam lapisan-lapisan yang tidak bisa kita kenali tanpa kesadaran spiritualitas. Jika para filsuf alam terdahulu banyak menghabiskan waktu dengan bahasa sains matematika, fisika, aljabar, alkimia (sebagai bahasa yang mereka anggap sebagai bahasa yang mampu menjelaskan alam) kini dengan teknologi yang kita miliki saat ini kita dapat mengenali susunan alam tersebut dengan lebih mudah. 
Citraan satelit dapat memprediksi lokasi planet atau bahkan tata surya lain, selain bumi dan Bima Sakti yang jaraknya millyaran tahun cahaya. Nanoteknologi memungkinkan kita melihat susunan atom yang memiliki konfigurasi fraktal, sistem modul komputer juga dapat memvisualisasikan panas temperatur bumi layaknya sebuah bentuk geografis yang memiliki simetri, dan berbagai alat lainnya dapat memudahkan kita dalam mengenali harmoni yang terdapat di alam ini.

Harmoni ada dalam bentuk matematikal, musikal dan aspek astronomikal yang mencapai puncaknya dalam analisis dari harmoni dari pergerakan planetplanet. Menyatukan semua pengetahuan yang berbeda dalam satu konsep harmoni bukan hanya diperbolehkan namun juga dibutuhkan. Dalam opini Kepler semua harmoni ini memiliki basis matematikal yang sama. Dasarnya ada pada hubungan geometrikal antara kuantitas fisikal yang memiliki hubungan numerikal antara bilangan bulat dan akhirnya dijadikan dasar harmoni Phytagorean. Untuk relasinya menjadi harmoni. Kepler berpendapat keindahan harmoni haruslah diterima oleh jiwa yang dimiliki manusia atau makhluk hidup lainnya. Sistem matahari yang diketemukan oleh Copernicus mengekspresikan harmoni yang didesain untuk dipusatkan di bagian tengah. Astronomi maka dari itu menjadi bidang pengetahuan yang paling tepat dan objektif untuk penemuan harmoni bagi Kepler.
Karya Somnium ini diharap dapat membawa pemirsanya pada sebuah pengalaman yang berpindah-pindah dari astronomi ke fantasi, dari optik ke kosmologi, perpindahan itulah yang membawa kita pada pengalaman perpindahan kesadaran menjadi ketidaksadaran dan rasional menjadi irasional. Dengan menggunakan perjalanan fiksi menuju bulan sebagai titik awal berkarya pemirsa diarahkan pada sebuah konsepsi tentang susunan alam.

\section{DAFTAR PUSTAKA}

Barker, Chris.

2014 Kamus Kajian Budaya.

Terjemahan: B. Hendar Putranto.

Yogyakarta: PT Kanisius.

Green, William.

2000 The Retail Store: Design and

Construction. Iuniverse: US.

Hatch, Mary Jo, Schultz, Majken.

2008 Taking Brand Initiative: How

Companies Can Align Strategy,

Culture, and Identity Through

Corporate Branding. USA: Josey

Bass

Mun, David,

1981, Shops: A Manual of Planning and

Design. London: The

Architectural Press

Santosa, Revianto Budi.

2000 Omah, Membaca Makna Rumah

Jawa. Yogyakarta :Yayasan

Bentang Budaya.

Wheeler, Alina.

2009 Designing Brand Identity: An

Essential Guide for the Whole 
Branding Team 3rd Edition.

Canada: John Willey \& Sons. Setyodarmodjo, Soenarko.

2007 Menggali filsafat dan budaya

Jawa. Jawa Timur: Lembaga

Javanologi Surabaya.
Perner, Lars,

2016, Consumer Behavior: The Pshycology Of Marketing, http://www.consumerpsychologi st.com/ 